Е.С. Шугрина

\title{
РАЗГРАНИЧЕНИЕ ПРЕДМЕТОВ ВЕДЕНИЯ И ПОЛНОМОЧИЙ РАЗНЫХ УРОВНЕЙ ПУБЛИЧНОЙ ВЛАСТИ В ОБЛАСТИ ОБРАЗОВАНИЯ
}

B соответствии с Конституцией РФ (ст. 43) право на образование является одним из основополагающих прав в Российской Федерации. Каждому гарантируется общедоступность и бесплатность дошкольного, основного общего и среднего профессионального образования в государственных и муниципальных образовательных учреждениях и на предприятиях. Основное общее образование обязательно. Родители или лица, их заменяющие обеспечивают получение детьми основного общего образования. Анализ указанных конституционных установлений позволяет сделать вывод о том, что роль органов государственной власти и органов местного самоуправления в сфере образования и обеспечения реализации прав граждан в этой сфере крайне велика.

Согласно ст. 71 Конституции РФ регулирование и защита прав и свобод человека и гражданина, в том числе и конституционное право на образование (ст. 43 Конституции РФ) находится в исключительном ведении РФ. В соответствии с подп. “е» ч. 1 ст. 72 Конституции РФ общие вопросы образования относятся к совместному ведению Российской Федерации и субъектов РФ. Данные положения конкретизированы в федеральных законах, законах субъектов РФ.

Поэтому представляется важным последовательный анализ не только особенностей разграничения предметов ведения и полномочий органов публичной власти в сфере образования, но и анализ гарантий конституционного права на образование.

\section{1. Общая характеристика предметов ведения и полномочий органов публичной власти}

Как уже говорилось выше, общие вопросы образования отнесены к совместному ведению Российской Федерации и ее субъектов. Предметы ведения субъектов РФ, вопросы местного значения в сфере образования перечислены в специальных федеральных законах, регулирующих особенности организации публичной власти в субъектах РФ и муниципальных образованиях соответственно. Так, в соответствии с ч. 1 ст. 26.3 Федерального закона от 6 октября 1999 г. №184-Ф3 (ред. от 2 июля 2013 г.) «Об общих принципах организации законодательных (представительных) и исполнительных органов государственной власти субъектов Российской Федерации» к полномочиям органов государственной власти субъекта РФ по предметам совместного ведения, осуществляемым данными органами самостоятельно за счет средств бюджета субъекта РФ (за исключением субвенций из федерального бюджета), относится решение вопросов:

- обеспечения государственных гарантий прав граждан на получение общедоступного и бесплатного дошкольного, начального общего, основного общего, среднего (полного) общего образования, а также дополнительного образования в общеобразовательных учреждениях путем выделения субвенций местным бюджетам в размере, необходимом для реализации основных общеобразовательных программ в части финансирования расходов на оплату труда работников общеобразовательных учреждений, расходов на учебники и учебные пособия, технические средства обучения, расходные материалы и хозяйственные нужды (за 
исключением расходов на содержание зданий и коммунальных расходов, осуществляемых из местных бюджетов) в соответствии с нормативами, установленными законами субъекта РФ;

- организация предоставления общего образования в государственных образовательных организациях субъектов РФ, создание условий для осуществления присмотра и ухода за детьми, содержания детей в государственных образовательных организациях субъектов РФ.

По данным вопросам органы государственной власти субъектов РФ имеют право принимать законы, иные нормативные правовые акты, в том числе региональные программы, вне зависимости от наличия в федеральных законах положений, устанавливающих указанное право.

Согласно ст. 14, 15 Федерального закона от 6 октября 2003 г. № 131-Ф3 (ред. от 2 июля 2013 г.) «Об общих принципах организации местного самоуправления в Российской Федерации» к вопросам местного значения муниципальных районов и городских округов отнесена организация предоставления общедоступного и бесплатного начального общего, основного общего, среднего (полного) общего образования по основным общеобразовательным программам, за исключением полномочий по финансовому обеспечению образовательного процесса, отнесенных к полномочиям органов государственной власти субъектов РФ; организация предоставления дополнительного образования детям (за исключением предоставления дополнительного образования детям в учреждениях регионального значения) и общедоступного бесплатного дошкольного образования на территории муниципального района, городского округа, а также организация отдыха детей в каникулярное время.

В ст. 6-9 нового Федерального закона от 29 декабря 2012 г. № 273 «Об образовании в Российской Федерации» (далее - ФЗ об образовании) перечислены полномочия федеральных органов государственной власти, органов государственной власти субъектов РФ и органов местного самоуправления. Причем следует особо обратить внимание на конструкцию ст. 7 Закона. В ней перечислены полномочия Российской Федерации в сфере образования, переданные для осуществления органам государственной власти субъектов РФ. Особенность осуществления данных полномочий связана, в частности, с финансированием и ответственностью. Финансовое обеспечение осуществления переданных полномочий осуществляется за счет субвенций из федерального бюджета, а также в пределах бюджетных ассигнований, предусмотренных в бюджете субъекта РФ на указанные цели не менее чем в размере планируемых поступлений в бюджет субъекта РФ от уплаты государственной пошлины, связанной с осуществлением переданных полномочий и зачисляемой в бюджет субъекта РФ в соответствии с Бюджетным кодексом РФ.

Рассмотрим полномочия органов власти с точки зрения отдельных элементов системы образования и разных уровней образования. Система образования включает в себя:

1. Федеральные государственные образовательные стандарты и федеральные государственные требования, образовательные стандарты, образовательные программы различных вида, уровня и (или) направленности.

Полномочия федеральных органов государственной власти:

- разработка и проведение единой государственной политики в сфере образования;

- утверждение федеральных государственных образовательных стандартов, установление федеральных государственных требований;

- разработка, утверждение и реализация государственных программ РФ, федеральных целевых программ, реализация международных программ в сфере образования;

К полномочиям органов государственной власти субъектов РФ относится:

- разработка и реализация региональных программ развития образования с учетом региональных социально-экономических, экологических, демографических, этнокультурных и других особенностей субъектов РФ;

Таким образом, основной объем по определению политики в области образования, стандартизации образовательной деятельности у федеральных органов государственной власти; органы государственной власти субъектов обладают лишь полномочиями по принятию региональных образовательных программ, отражающих особенности соответствующего региона.

2. Организации, осуществляющие образовательную деятельность, педагогических работников, обучающихся и родителей (законных представителей) несовершеннолетних обучающихся.

Полномочия федеральных органов государственной власти:

- организация предоставления высшего образования, включая обеспечение государственных гарантий реализации права на получение на конкурсной основе бесплатно высшего образования;

- организация предоставления дополнительного профессионального образования в федеральных государственных образовательных организациях; 
- создание, реорганизация, ликвидация федеральных государственных образовательных организаций, осуществление функций и полномочий учредителя федеральных государственных образовательных организаций;

- -лицензирование образовательной деятельности:

а) организаций, осуществляющих образовательную деятельность по образовательным программам высшего образования;

б) федеральных государственных профессиональных образовательных организаций, реализующих образовательные программы среднего профессионального образования в сферах обороны, производства продукции по оборонному заказу, внутренних дел, безопасности, ядерной энергетики, транспорта и связи, наукоемкого производства по специальностям, перечень которых утверждается Правительством РФ;

в) российских образовательных организаций, расположенных за пределами территории РФ, образовательных организаций, созданных в соответствии с международными договорами РФ, а также осуществляющих образовательную деятельность дипломатических представительств и консульских учреждений РФ, представительств РФ при международных (межгосударственных, межправительственных) организациях;

г) иностранных образовательных организаций, осуществляющих образовательную деятельность по месту нахождения филиала на территории РФ;

- -государственная аккредитация образовательной деятельности организаций, осуществляющих образовательную деятельность, а также иностранных образовательных организаций, осуществляющих образовательную деятельность за пределами территории РФ.

К полномочиям федеральных органов государственной власти, переданным органам государственной власти субъектов РФ относятся:

- -лицензирование образовательной деятельности организаций, осуществляющих образовательную деятельность на территории субъекта РФ;

- -государственная аккредитация образовательной деятельности организаций, осуществляющих образовательную деятельность на территории субъекта РФ.

К полномочиям органов государственной власти субъектов РФ относится:

- -создание, реорганизация, ликвидация образовательных организаций субъектов РФ, осуществление функций и полномочий учредителей образовательных организаций субъектов РФ;

- -обеспечение государственных гарантий реализации прав на получение общедоступного и бесплат- ного дошкольного образования в муниципальных дошкольных образовательных организациях, общедоступного и бесплатного дошкольного, начального общего, основного общего, среднего общего образования в муниципальных общеобразовательных организациях, обеспечение дополнительного образования детей в муниципальных общеобразовательных организациях посредством предоставления субвенций местным бюджетам, включая расходы на оплату труда, приобретение учебников и учебных пособий, средств обучения, игр, игрушек (за исключением расходов на содержание зданий и оплату коммунальных услуг), в соответствии с нормативами, определяемыми органами государственной власти субъектов РФ;

- организация предоставления общего образования в государственных образовательных организациях субъектов РФ;

- создание условий для осуществления присмотра и ухода за детьми, содержания детей в государственных образовательных организациях субъектов РФ;

- финансовое обеспечение получения дошкольного образования в частных дошкольных образовательных организациях, дошкольного, начального общего, основного общего, среднего общего образования в частных общеобразовательных организациях, осуществляющих образовательную деятельность по имеющим государственную аккредитацию основным общеобразовательным программам, посредством предоставления указанным образовательным организациям субсидий на возмещение затрат, включая расходы на оплату труда, приобретение учебников и учебных пособий, средств обучения, игр, игрушек (за исключением расходов на содержание зданий и оплату коммунальных услуг), в соответствии с нормативами, указанными в п. 3 ч. 1 ст. 8 ФЗ об образовании;

- организация предоставления среднего профессионального образования, включая обеспечение государственных гарантий реализации права на получение общедоступного и бесплатного среднего профессионального образования;

- организация предоставления дополнительного образования детей в государственных образовательных организациях субъектов РФ;

- организация предоставления дополнительного профессионального образования в государственных образовательных организациях субъектов РФ;

- организация обеспечения муниципальных образовательных организаций и образовательных 
организаций субъектов РФ учебниками в соответствии с федеральным перечнем учебников, рекомендованных к использованию при реализации имеющих государственную аккредитацию образовательных программ начального общего, основного общего, среднего общего образования организациями, осуществляющими образовательную деятельность, и учебными пособиями, допущенными к использованию при реализации указанных образовательных программ;

- организация предоставления психолого-педагогической, медицинской и социальной помощи обучающимся, испытывающим трудности в освоении основных общеобразовательных программ, своем развитии и социальной адаптации.

K полномочиям органов местного самоуправления относится:

- организация предоставления общедоступного и бесплатного дошкольного, начального общего, основного общего, среднего общего образования по основным общеобразовательным программам в муниципальных образовательных организациях (за исключением полномочий по финансовому обеспечению реализации основных общеобразовательных программ в соответствии с федеральными государственными образовательными стандартами);

- организация предоставления дополнительного образования детей в муниципальных образовательных организациях (за исключением дополнительного образования детей, финансовое обеспечение которого осуществляется органами государственной власти субъекта РФ);

- создание условий для осуществления присмотра и ухода за детьми, содержания детей в муниципальных образовательных организациях;

- создание, реорганизация, ликвидация муниципальных образовательных организаций (за исключением создания органами местного самоуправления муниципальных районов муниципальных образовательных организаций высшего образования), осуществление функций и полномочий учредителей муниципальных образовательных организаций;

- обеспечение содержания зданий и сооружений муниципальных образовательных организаций, обустройство прилегающих к ним территорий;

- учет детей, подлежащих обучению по образовательным программам дошкольного, начального общего, основного общего и среднего общего образования, закрепление муниципальных образовательных организаций за конкретными тер- риториями муниципального района, городского округа.

Кроме того, органы местного самоуправления муниципальных районов имеют право на осуществление функций учредителей муниципальных образовательных организаций высшего образования, находящихся в их ведении по состоянию на 31 декабря 2008 г. Органы местного самоуправления городских округов вправе обеспечивать организацию предоставления на конкурсной основе высшего образования в муниципальных образовательных организациях высшего образования.

Вышеприведенный перечень полномочий органов публичной власти показывает, что федеральные органы государственной власти обеспечивают создание федеральных образовательных организаций, лицензирование образовательной деятельности. С определенной долей условности можно сказать, что федеральные органы власти «отвечают» за получение дополнительного профессионального образования и общедоступного и бесплатного высшего образования; органы государственной власти субъектов - за общедоступное и бесплатное среднее профессиональное образование, дополнительное образование детей; органы местного самоуправления - за общедоступное и бесплатное школьное и дошкольное образование, дополнительное образование в муниципальных образовательных организациях, отдых детей в каникулярное время.

3. Федеральные государственные органы и органы государственной власти субъектов Российской Федерации, осуществляющие государственное управление в срере образования, и органы местного самоуправления, осуществляющие управление в сфере образования, созданные ими консультативные, совещательные и иные органы.

Согласно ч. 3 ст. 89 ФЗ об образовании государственное управление в сфере образования осуществляют в пределах своих полномочий федеральные органы государственной власти и органы государственной власти субъектов РФ. В муниципальных районах и городских округах управление в сфере образования осуществляется соответствующими органами местного самоуправления.

Федеральными органами исполнительной власти, осуществляющими государственное управление в сфере образования, являются федеральный орган исполнительной власти, осуществляющий функции по выработке государственной политики и нормативно-правовому регулированию в сфере образования, федеральный орган исполнительной власти, осуществляющий функции по контролю и надзору в сфере образования, а также федеральные государственные органы, имеющие в своем ведении образовательные организации. Федеральный орган исполнительной власти, осуществляю- 
щий функции по выработке государственной политики и нормативно-правовому регулированию в сфере образования, осуществляет координацию деятельности в сфере образования федеральных государственных органов, органов исполнительной власти субъектов РФ и иных субъектов системы образования. В настоящее время таким органом является Министерство образования и науки РФ․

Органы государственной власти субъектов РФ муниципальных образований, осуществляющие управление в сфере образования, определяются сами субъектами РФ, муниципальными образованиями. Например, министерство образования ${ }^{2}$, комитет общего и профессионального образования ${ }^{3}$, комитет по образованию местной администрации (структурное подразделение местной администрации) ${ }^{4}$.

4. Организации, осуществляющие обеспечение образовательной деятельности, оценку качества образования.

Полномочия федеральных органов государственной власти:

- государственный контроль (надзор) в сфере образования за деятельностью организаций, а также органов исполнительной власти субъектов РФ, осуществляющих государственное управление в сфере образования;

- разработка прогнозов подготовки кадров, требований к подготовке кадров на основе прогноза потребностей рынка труда;

- обеспечение осуществления мониторинга в системе образования на федеральном уровне;

- формирование и ведение федеральных информационных систем, федеральных баз данных в сфере образования, в том числе обеспечение конфиденциальности содержащихся в них персо-

1 Указ Президента РФ от 4 марта 2010 г. 271 (ред. от 21 мая 2012 г.) «Вопросы Министерства образования и науки Российской Федерации»; Постановление Правительства РФ от 6 июня 2013 г. № 466 (ред. от 9 августа 2013 г.) «Об утверждении Положения о Министерстве образования и науки Российской Федерации».

2 См., напр.: Постановление Губернатора Новосибирской области от 26 мая 2010 г. № 162 (ред. от 18 января 2013 г.) «О министерстве образования, науки и инновационной политики Новосибирской области».

3 См, напр.: Постановление Правительства Ленинградской области от 11 августа 2008 г. № 238 (ред. от 28 декабря 2012 г.) «Об утверждении Положения о комитете общего и профессионального образования Ленинградской области».

4 См., напр.: Решение Совета Омского муниципального района Омской области от 27.08.2009 № 68 (ред. от 20.06.2013) «Об утверждении Положения о Комитете по образованию Администрации Омского муниципального района Омской области». нальных данных в соответствии с законодательством РФ;

- установление и присвоение государственных наград, почетных званий, ведомственных наград и званий работникам системы образования.

K полномочиям федеральных органов государственной власти, переданным органам государственной власти субъектов РФ относятся:

- государственный контроль (надзор) в сфере образования за деятельностью организаций, осуществляющих образовательную деятельность на территории субъекта РФ, а также органов местного самоуправления, осуществляющих управление в сфере образования на соответствующей территории;

- подтверждение документов об образовании и (или) о квалификации.

К полномочиям органов государственной власти субъектов РФ относится:

- обеспечение осуществления мониторинга в системе образования на уровне субъектов РФ;

Очевидно, что функции государственного контроля, обеспечения качества образования возложены на органы государственной власти, в первую очередь на федеральные органы государственной власти.

5. Объединения юридических лии, работодателей и их объединений, общественные объединения, осуществляющие деятельность в сфере образования.

Право на объединение является самостоятельным конституционным правом, предусмотренным в ст. 30 Конституции РФ. В этом смысле государство не может принуждать или обязывать к таким объединениям, но может создавать условия, стимулирующие объединения различных организаций в сфере образования.

Полномочия органов публичной власти реализуются опосредованно, в частности, при определении единой государственной политики в сфере образования, обеспечении мониторинга и контроля за качеством образовательной деятельности, обеспечения гарантий получения образования, принятия единых стандартов образовательной деятельности, лицензирования и аккредитации образовательных организаций.

Несмотря на достаточное разнообразие формулировок полномочий, можно выделить определенные категории полномочий:

- полномочия, по которым соответствующие органы публичной власти осуществляют весь комплекс организационно-правовых, организационно- технических мероприятий и распорядительных действий по управлению отношениями в соответствующей сфере деятельности, обеспечению скоординированной деятельности, направленной на достижение заданного результата, цели - реализации социальной от- 
ветственности, предоставление услуг (формулировка начинается с термина «организация»; например, организация предоставления общего образования в государственных образовательных организациях субъектов РФ); в этом случае соответствующий орган власти отвечает за конечный результат, за то, чтобы была оказана соответствующая услуга;

- полномочия, по которым соответствующие органы публичной власти принимают меры, позволяющие достичь и (или) сохранить обстоятельства, обстановку, необходимую для реализации, предоставление услуг иными субъектами хозяйственной деятельности, и ответственны за создание инфраструктуры для оказания услуг, а не за само предоставление конкретной услуги (формулировка начинается с термина "создание условий», «обеспечение условий»; например, создание условий для осуществления присмотра и ухода за детьми, содержания детей в муниципальных образовательных организациях); в этом случае соответствующий орган власти отвечает за процесс, но не за результат;

- полномочия, сформулированные прямо как предоставление соответствующей услуги или осуществление соответствующего вида деятельности (например, подтверждение документов об образовании и (или) о квалификации); в этом случае орган власти также отвечает за конечный результат.

Анализ формулировок полномочий органов публичной власти показывает, что большинство формулировок нацелено на четкое понимание конечного результата, т.е. той услуги, которая должна быть оказана. Такой подход следует, безусловно, приветствовать, поскольку исключается дублирование полномочий разных органов публичной власти.

Новый федеральный закон об образовании выполняет роль кодификационного акта в сфере образования. С его вступление в силу утратили силу многочисленные документы, регулировавшие отдельные отношения в сфере образования. Федеральные законы, регулирующие особенности организации публичной власти в субъектах РФ, муниципальных образования приведены в полное соответствие с новым законом об образовании.

Существующий механизм разграничения предметов ведения и полномочий органов публичной власти в сфере образования, содержащийся в федеральных законах нацелен на устранение дублирования и пробельности, которая была характерна для этой сферы все последние годы ${ }^{5}$. Наступил этап разработки подзаконных актов, соз-

См. напр.: Нарутто С.В. О некоторых проблемах законодательства об образовании и его систематизации // Юридическое образование и наука. - 2012. - № 2. - С. 22-26. дающих механизмы реализации законодательных норм. Кроме того, в подавляющем большинстве субъектов РФ ситуация иная - не везде внесены необходимые изменения в региональные нормативные акты, нормативные правовые акты субъектов РФ не в полном объеме приведены в соответствие с федеральными. По тем полномочиям, в рамках которых должна быть предоставлена публичная услуга, отсутствует необходимый пакет административных регламентов - это касается всех трех уровней публичной власти.

\section{2. Особенности полномочий органов публичной власти по созданию системы гарантий права граждан на получение бесплатного образования}

Гарантированность образования - это его неотъемлемый атрибут, который закреплен как в международном, так и в российском национальном праве. Гарантии служат тем мостиком, который обеспечивает переход от общего к частному, от прокламируемой возможности к действию. Иными словами, право на образование останется очередной декларацией до тех пор, пока в России не будет функционировать эффективная система его гарантий.

Гарантия (от фр. garantee) - «ручательство», «поручительство», «порука», «обеспечение», «заверение» и др ${ }^{6}$. Очевидно, что право может быть реализовано только тогда, когда ему соответствует обязанность государства или другого лица (органа) его обеспечить.

В перечень гарантий прав и свобод человека и гражданина входят: выявление фактов нарушений прав и свобод; средства их восстановления; меры юридической ответственности; меры пресечения действий, нарушающих права и свободы или создающих тому угрозу; процессуальные формы (процедуры) охраны прав и свобод. В большинстве случаев те или иные способы защиты используются в различных комбинациях. Причем, поскольку нарушение или прочие посягательства на право или свободу в принципе могут иметь место в любой стадии их реализации, постольку необходимость в их охране может возникнуть в любой момент, а затем реализация продолжается в обычном порядке ${ }^{7}$. Система гарантий права на образование, закрепляемая действующим законодательством, охватывает всю совокупность условий и средств, обеспечивающих их реализацию и правовую защиту.

6 Даль В. Толковый словарь живого великорусского языка: в 4 т. T. 1. - M., 1994. - С. 344.

Гражданские права человека: современные проблемы теории и практики / под ред. Ф.М. Рудинского. - М., 2006. - С. 355. 
Образование - единый целенаправленный процесс воспитания и обучения, являющийся общественно значимым благом и осуществляемый в интересах человека, семьи, общества и государства, а также совокупность приобретаемых знаний, умений, навыков, ценностных установок, опыта деятельности и компетенции определенных объема и сложности в целях интеллектуального, духовно-нравственного, творческого, физического и (или) профессионального развития человека, удовлетворения его образовательных потребностей и интересов

Согласно ст. 10 ФЗ об образовании образование подразделяется на общее образование, профессиональное образование, дополнительное образование и профессиональное обучение, обеспечивающие возможность реализации права на образование в течение всей жизни (непрерывное образование).

Общее образование и профессиональное образование реализуются по уровням образования.

В Российской Федерации устанавливаются следующие уровни общего образования: 1) дошкольное образование; 2) начальное общее образование; 3) основное общее образование; 4) среднее общее образование.

В Российской Федерации устанавливаются следующие уровни профессионального образования: 1) среднее профессиональное образование; 2) высшее образование - бакалавриат; 3) высшее образование - специалитет, магистратура; 4) высшее образование - подготовка кадров высшей квалификации.

Дополнительное образование включает в себя такие подвиды, как дополнительное образование детей и взрослых и дополнительное профессиональное образование.

Федеральный законодатель подчеркивает, что система образования создает условия для непрерывного образования посредством реализации основных образовательных программ и различных дополнительных образовательных программ, предоставления возможности одновременного освоения нескольких образовательных программ, а также учета имеющихся образования, квалификации, опыта практической деятельности при получении образования.

Очевидно, что система гарантий должна обеспечивать определенный набор благ в отношении любого уровня образования; для отдельный видов образования либо для отдельных категорий обучающихся могут быть установлены дополнительные гарантии.

Государственные гарантии реализации права граждан на образование в Российской федерации в общем виде перечислены в ст. 5 ФЗ об образовании. К таким гарантиям, в частности, отнесено следующее:
1. Право на образование в Российской Федерации гарантируется независимо от пола, расы, национальности, языка, происхождения, имущественного, социального и должностного положения, места жительства, отношения к религии, убеждений, принадлежности к общественным объединениям, а также других обстоятельств.

2. В Российской Федерации гарантируются общедоступность и бесплатность в соответствии с федеральными государственными образовательными стандартами дошкольного, начального общего, основного общего и среднего общего образования, среднего профессионального образования, а также на конкурсной основе бесплатность высшего образования, если образование данного уровня гражданин получает впервые.

3. В Российской Федерации реализация права каждого человека на образование обеспечивается путем создания федеральными государственными органами, органами государственной власти субъектов РФ и органами местного самоуправления соответствующих социально-экономических условий для его получения, расширения возможностей удовлетворять потребности человека в получении образования различных уровня и направленности в течение всей жизни.

4. В целях реализации права каждого человека на образование федеральными государственными органами, органами государственной власти субъектов РФ и органами местного самоуправления:

1) создаются необходимые условия для получения без дискриминации качественного образования лицами с ограниченными возможностями здоровья, для коррекции нарушений развития и социальной адаптации, оказания ранней коррекционной помощи на основе специальных педагогических подходов и наиболее подходящих для этих лиц языков, методов и способов общения и условия, в максимальной степени способствующие получению образования определенного уровня и определенной направленности, а также социальному развитию этих лиц, в том числе посредством организации инклюзивного образования лиц с ограниченными возможностями здоровья;

2) оказывается содействие лицам, которые проявили выдающиеся способности и к которым в соответствии с настоящим Федеральным законом относятся обучающиеся, показавшие высокий уровень интеллектуального развития и творческих способностей в определенной сфере учебной и научно-исследовательской деятельности, в научно-техническом и художественном творчестве, в физической культуре и спорте;

3) осуществляется полностью или частично финан- 
совое обеспечение содержания лиц, нуждающихся в социальной поддержке в соответствии с законодательством РФ, в период получения ими образования.

В Законе установлены дополнительные гарантии для:

- отдельных категорий обучающихся (лиц, проявивших выдающиеся способности, иностранных граждан и лиц без гражданства, лиц с ограниченными возможностями здоровья, лиц осужденных к лишению свободы, к принудительным работам, подозреваемым и обвиняемым, содержащимся под стражей);

- отдельных направлений образования (подготовка кадров в интересах обороны и безопасности государства, обеспечения законности и правопорядка; в сфере медицинского образования и фармацевтического образования; в области искусств, физической культуры и спорта; подготовка специалистов авиационного персонала гражданской авиации, членов экипажей судов в соответствии с международными требованиями, а также в области подготовки работников железнодорожного транспорта, непосредственно связанных с движением поездов и маневровой работой; подготовка несовершеннолетних обучающихся к военной или иной государственной службе);

- в области изучения основ духовно-нравственной культуры народов РФ, получения теологического и религиозного образования;

- для отдельных образовательных учреждений (в загранучреждениях Министерства иностранных дел РФ).

Как уже говорилось ранее, федеральным законодательством установлены и государственные гарантии реализации права на образование (в т.ч. бесплатного) которые должны обеспечиваться органами государственной власти субъектов РФ путем выделения субвенций местным бюджетам в размере, необходимом для реализации основных общеобразовательных программ в части финансирования расходов на (нормативы расходов, устанавливаются законами субъекта РФ):

- оплату труда работников общеобразовательных учреждений,

- учебники и учебные пособия,

- технические средства обучения,

- расходные материалы и хозяйственные нужды (за исключением расходов на содержание зданий и коммунальных расходов, осуществляемых из местных бюджетов).

Очевидно, что все органы публичной власти обязаны обеспечивать реализацию федеральных гарантий. Для этого в субъектах РФ, муниципальных образованиях принимаются свои нормативные правовые акты. Например, в Административном регламенте по предоставле- нию муниципальной услуги «Предоставление общедоступного бесплатного дошкольного образования детям» на территории муниципального образования - Шацкий муниципальный район Рязанской области, утвержденном Постановлением Администрации муниципального образования - Шацкий муниципальный район Рязанской области от 25 марта 2013 г. № 258 прямо указывается, что одним из результатов предоставления муниципальной услуги «Предоставление общедоступного бесплатного дошкольного образования детям» является обеспечение государственных гарантий прав граждан на получение общедоступного бесплатного дошкольного образования. В Ульяновской области принято Постановление Правительства Ульяновской обл. от 18 июля 2013 г. № 303-П «Об обеспечении государственных гарантий реализации прав граждан на получение общедоступного и бесплатного общего образования в муниципальных общеобразовательных организациях Ульяновской области, расположенных в поселках городского типа (рабочих поселках) Ульяновской области».

Вместе с тем, в нормативных правовых актах субъектов РФ, муниципальных образований могут быть установлены дополнительные гарантии реализации права на образование, в том числе бесплатное. Например, в Москве принят Закон от 30 ноября 2005 г. № 61 (ред. от 25 июня 2008 г.) «О дополнительных гарантиях по социальной поддержке детей-сирот и детей, оставшихся без попечения родителей, в городе Москве». Хотя, как правило, стать, содержащие гарантии права на образования содержатся в законах субъектов РФ об образовании. Так, в ст. 16 Закона Московской области от 27 июля 2013 г. № 94/2013-О3 «Об образовании» предусматриваются дополнительные меры по реализации в Московской области прав граждан на образование; одной из таких мер является предоставление студентам образовательных организаций высшего образования возможности овладения квалифицированными рабочими профессиями.

В докладе Тульской областной Думы «О состоянии законодательства Тульской области в 2010 г.», утвержденном Постановлением Тульской областной Думы от 16 декабря 2010 г. № 18/815 отмечалось, что впервые Законом области ${ }^{8}$ закреплено право за детьми-сиротами и детьми, оставшимися без попечения родителей, воспитывающимися в опекунских и приемных семьях, на получение путевок в загородные оздоровительные лагеря и иные организации отдыха детей и их оздоровления за счет средств бюджета области.

\footnotetext{
Речь идет о Законе Тульской области от 7 октября 2009 г. № 1336-3ТО «О защите прав ребенка».
} 
В докладе «О состоянии законодательства Республики Башкортостан в 2012 г.», утвержденном Постановлением Государственного Собрания - Курултая РБ от 31 января 2013 г. № ГС-2764 констатируется, что Законом Республики Башкортостан от 7 марта 2012 г. № 519-3 «О внесении изменений в Закон Республики Башкортостан «О дополнительных гарантиях по социальной поддержке детей-сирот и детей, оставшихся без попечения родителей» с учетом новаций федерального законодательства уточнены дополнительные гарантии права указанной категории детей на образование. Данным Законом предусмотрено, что дети-сироты и дети, оставшиеся без попечения родителей, имеют право на бесплатную юридическую помощь в соответствии с Федеральным законом от 21 ноября 2011 г. № 324-Ф3 «О бесплатной юридической помощи в Российской Федерации».

В ст. 12 Устава города Ростова-на-Дону от 9 апреля 1996 г. № 211 (ред. от 18 июня 2013 г.) предусматривается, что детям, получающим начальное общее и основное общее образование, обеспечивается льготное или бесплатное питание, бесплатное медицинское обслуживание, льготный проезд на транспорте. Дети из малообеспеченных семей пользуются дополнительными гарантиями социальной защиты. Органы самоуправления оказывают содействие в создании условий для получения в городе элитарного образования гражданами, проявившими выдающиеся способности, в том числе посредством поощрения организации и деятельности нетиповых образовательных учреждений высшей категории, учреждения специальных муниципальных стипендий для особо одаренных. Аналогичные нормы есть и в уставах других муниципальных образований Ростовской области.

Можно приводить и другие аналогичные примеры. Таким образом, и на уровне субъектов РФ и на уровне муниципальных образований предоставляются дополнительные гарантии реализации права на образования, в том числе бесплатного. Вместе с тем следует констатировать, что большинство действующих в субъектах РФ и муниципальных образованиях нормативных правовых актах, соответствует скорее букве и духе утратившего силу Закона РФ «Об образовании», чем нового Федерального закона «Об образовании в Российской Федерации».

\section{Библиографический список:}

1. Даль В. Толковый словарь живого великорусского языка: в 4 т. Т. 1. - М., 1994.

2. Гражданские права человека: современные проблемы теории и практики / под ред. Ф.М. Рудинского. - М., 2006.

3. Нарутто С.В. О некоторых проблемах законодательства об образовании и его систематизации // Юридическое образование и наука. - 2012. - № 2. С. 22-26.

4. Нарутто С.В. Действие и реализация образовательного законодательства // административное и муниципальное право. - 2012. - № 8. - С. 42-49.

5. Шугрина Е.С. Автономия вуза и академические свободы: соотношение международного и национального правового регулирования // Актуальные проблемы российского права. - 2013. - № 8. - С. 1041-1049.

6. Шугрина Е.С., Нарутто С.В. Особенности управления системой образования в правоприменительной деятельности // Административное и муниципальное право. - 2012. - № 6. - С. 43-58.

\section{References (transliteration):}

1. Dal' V. Tolkovyi slovar' zhivogo velikorusskogo yazyka: v 4 t. T. 1. - M., 1994.

2. Grazhdanskie prava cheloveka: sovremennye problemy teorii i praktiki / pod red. F.M. Rudinskogo. - M., 2006.

3. Narutto S.V. O nekotoryh problemah zakonodatel'stva ob obrazovanii i ego sistematizacii // Yuridicheskoe obrazovanie i nauka. - 2012. - № 2. S. 22-26.

4. Narutto S.V. Deistvie i realizaciya obrazovatel'nogo zakonodatel'stva // administrativnoe i municipal'noe pravo. 2012. - № 8. - S. 42-49.

5. Shugrina E.S. Avtonomiya vuza i akademicheskie svobody: sootnoshenie mezhdunarodnogo i nacional'nogo pravovogo regulirovaniya // Aktual'nye problemy rossiiskogo prava. - 2013. - № 8. - S. 1041-1049.

6. Shugrina E.S., Narutto S.V. Osobennosti upravleniya sistemoi obrazovaniya v pravoprimenitel'noi deyatel'nosti // Administrativnoe i municipal'noe pravo. - 2012. - № 6. - S. 43-58. 